On the following morning, he was in a soporose condition, and could not answer questions rationally. His tongue was dry and brown; the legs were slightly cedematous. There were erythematous patches over legs and arms, and a vesicular eruption over arms and face. The pulse was a little full, but very compressible. The patient had much thirst. The bowels had been loosely opened, but were not relaxed; and he did not resent pressure over the abdomen. He had no spots like those of fever, no injection of conjunctivæ, and no delirium. The skin was hot and moist; the face pale. No affection of lungs or heart could be detected on physical examination. The urine was slightly albuminous. He was directed to con. tinue the nourishment and wine. He appeared much the same in the evening.

October 5th. The legs were less swollen; the erythema less marked; and he appeared a trifle better. He had taken the nourishment well. In the evening he was asleep and breathing easily on my visit to the ward; and was, therefore, not disturbed, as he was reported to have had very little rest since admission.

Octoher 6 th, I was summoned early in the morning, and found him sinking, apparently from exhaustion. Wine was ordered, which regurgitated, and he sank about $12 \mathrm{~A}$ M.

The body was examined three days after death by direction of the coroner. The weather was warm. Rigor mortis was slightly marked. The face was calm. Vesicular spots were seen over the arms. There was some subcuticular lividity of the legs, and sugillation on the posterior part of the trunk. There was abrasion of the skin over the left elbow. The œdema of the legs had almost disappeared. There was very little fat in the abdominal wall or around the viscera.

Head. The scalp was natural ; the calvarium thin; the dura mater normal. There was some subarachnoid effusion; the pia mater was somewhat injected. The brain-substance was consistent, a little more vascular than usual; and the white substance of the hemispheres had a fine pinkish tint. A little fluid was found in the ventricles, and about an ounce of serum in the base of the skull. The cerebral vessels were healthy. The sinuses were filled with dark fluid blood.

Chest. Old pleural adhesions were present, especially on the left side. Some serum was found in the right pleura. The lungs were pale anteriorly, but congested behind; they crepitated well. The bronchial tubes were healthy, and contained a very slight amount of secretion. There was a slight appearance of scattered tubercle at the apices; no consolidation. The trachea was pale. The heart weighed eight and a half ounces; it was healthy. There was a black cuagulum in the right auricle, passing down into the ventricle, where it became partly decolorised and firmly interlaced with the columnæ carneæ, extending thence for some inches into the pulmonary artery, where it again became black. Dark fluid blood escaped from the pulmonary veins on section. Dark coagula were found in the left side of the heart. The valves were healthy. The aorta was healthy. About an ounce and a half of serum was found in the pericardium.

Abdomen. The stomach contained about two or three ounces of yellow fluid of acid reaction. The mucous membrane was pale and softened. There was some prominence of the veins, and pigmentary discoloration, but no vascularity. The pancreas was firm; apparently healthy. The spleen was small, pale, firm. No fluid was found in the peritoneum. The bladder was nearly empty. The liver was pale; the gallbladder contained some dark bile, but was not distended. 'The right kidney weighed five ounces and a half; it was large, pale not granular; the capsule separated well. The left weighed five ounces, and presented much the same characters. The intestines, opened throughout, contained no solid fæcal matter, but a small quantity of yellowish brown fluid and yellowish flakes. No ulceration or prominence of the Peyerian patches was seen; and there was no lymph on the serous coat. The ileum was injected for two or three inches, about nine inches from the cæcum, and at two or three spots higher up. The large intestines were healthy. The coats of the intestines seemed thin.

Remarks. In this case, during life, there was absence of positive disease; no proof of chest affection, no evidence of specific fever (typhus or typhoid), or of organic disease of the liver, heart, or kidney; the odema subsiding rapidly on rest. There was not the flush of fever, no spots, pain over the belly, diarrhœa, delirium, nor subsultus occurring before death. The albumen in the urine was probably a transient condition as it is not uncommon in persons subjected to exposure, from causes readily appreciated. Excluding the diseases enumerated, the dirty state and offensive odour of the patient, the dry brown tongue, hot breath, thirst, prostration, with excitement, œdema gradually disappearing, and rapid exhaustion (with the collateral evidence or even without it), induced me to conclude that death occurred from exhaustion, the result of destitution.*

The post mortem appearances confirmed the opinion. There was no ulceration of the intestines; no visceral disease; and the blood was not fluid. The appearances were, in fact, negative, except the fine pink tint of the brain, the serum in the skull, and the injection of the small intestines. The alimentary canal contained no freal matter; there was marked emsciation; and the clots in the heart pointed to death from asthenia.

\section{CASE OF SEVERE POST PARTUM $\mathrm{H}$ A MOR R H A E。}

By Thomas T. Blease, Esq., Altrincham.

THE following case I have been induced to narrate, from an impression that it would interest a fair share of the readers of this JourNaL; not only because it points out to what an amount of severe treatment the human female can be subjected without suffering any serious consequences, but also on account of the way in which the hæmorrhage was suppressed, viz., by the plugging of the uterus, and not the vagina. Taking into consideration the success of the treatment, the question arises, whether, if the same had been adopted in fatal cases, their termination would have been such.

CASE. On the afternoon of Tuesday, October 5th, 1858, I was summoned to attend in labour Mrs. H., who resided three miles from my house. I arrived about half-past five, and found the os uteri fully dilated, the membranes entire, and the vertex presenting, though situated very high. After waiting an hour, I ruptured the membranes; the uterine contractions, previously strong and frequent, were now almost unin terrupted. In the course of two or three hours, the head began to enter the cavity of the pelvis, but made no further progress. Knowing that my father had delivered her in her first (the present being her second) accouchement with the forceps, after she had been in labour a day or two, symptoms arising which called for immediate delivery, I completed the la bour with the assistance of the forceps, at 11 P.M., five hours and a half from the time of my arrival. The child, a very fine one though exhibiting few signs of animation, was soon resuscitated. The placenta was expelled in twenty minutes or less and the patient appeared to be going on satisfactorily. I had a female manipulating and pressing the abdomen from the birth of the child. In a few moments, symptoms of internal hæmorrhage manifesting themselves, I applied my hand to the denuded abdomen, when I found the uterus large, but on firm pressure, it contracted, and expelled a large quantity of coagula. I administered half an ounce of ergot in divided doses ; in addition, I introduced my hand into the cavity of the uterus, but could not get it into a state of permanent contraction. The uterus relaxed still more, and the hæmorrhage continued, although I irritated its internal surface with my left hand, while I compressed it with the right externally. I poured cold water from a height suddenly, and also in a con tinuous stream, upon the patient's bare abdomen, but all to no purpose. As a last resource, I plugged the uterus with a large piece of linen steeped in cold water; I then applied cold wet napkins to the lower parts of the person, and a large corn. press over the uterus, secured with a bandage; and, after waiting a reasonable time, finding my patient rallying a little, and knowing that it was almost impossible for the hæmorrhage to recur, I left her. In the course of a few hours, my father called, and withdrew the plug, without a repetition of the flooding.

The only medicine the patient took, was one grain of solid opium, and a little castor oil. Her recovery was complete.

* Destitution compreheuds want of food, proper lodging, aud rest. I have, unfortunately, had too much experience of it; but the examples have been less severe than the one detailed, not proving directly fatal. It is one of the most important elements in parochial practice, modifying considerably the type and treatment of disease. I regard cases of pure starvation to be of very rare occurrence. 